\title{
МАТЕМАТИЧЕСКАЯ МОДЕЛЬ И МЕТОД РАСЧЕТА ДИНАМИКИ СУШКИ И ТЕРМОДЕСТРУКЦИИ БИОМАССЫ
}

Сороковая Н.Н. д.т.н., с.н.с., Коринчук Д.Н. к.т.н., с.н.с.

Институт технической теплофизики Национальной академии наук Украины, г. Киев

\begin{abstract}
Аннотация. Разработана математическая модель и численный метод расчета динамики тепломассопереноса, фазовых превращений и усадки при сушке коллоидных капиллярно-пористых тел ичилиндрической формы в условиях равномерного обдува теплоносителем. Математическая модель строилась на базе дифференциального уравнения переноса субстанции (энергии, массы, импульса) в деформируемых системах. Проведены экспериментальные исследования кинетики обезвоживания частиц энергетической вербы в потоке воздуха с изелью верификации математической модели. Обоснована возможность ее использования для расчета совместных прочессов сушки и начального этапа термического разложения биомассы. С использованием ранее полученных данных по значениям энергии активации $A_{\ni ф}(T)$ для различных видов биомассы проведено математическое моделирование динамики и кинетики высокотемпературной сушки в потоке дымовых газов энергетической вербы, которая сопровождается термодеструкцией гемиочеллюлозы. Результаты численных экспериментов свидетельствуют об адекватности предложенного подхода, эффективности математической модели и метода ее реализации. На их основе возможно проводить исследование динамики тепломассопереноса при сушке частии различных видов измельченной биомассы; определение температуры начала и окончания первой стадии термического разложения; момента достижения равновесного влагосодержания в зависимости от свойств материала и сушильного агента. Эти данные позволяют выбирать оптимальные с точки зрения сохранения энергии и качества высушиваемого продукта режимные параметры процесса.
\end{abstract}

Ключевые слова: биомасса, сушка, термодеструкция, математическое моделирование, цилиндрическая частица, барабанная сушилка, энергия активации.

\section{MATHEMATICAL MODEL AND METHOD FOR CALCULATING THE DYNAMICS OF DRYING AND THERMODESTRUCTION OF BIOMASS}

\author{
Sorokova N.N., Korinchuk D.N. \\ Institute of Engineering Thermophysics of the National Academy of Sciences of Ukraine, Kiev
}

\begin{abstract}
A mathematical model and a numerical method for calculating the dynamics of heat and mass transfer, phase transformations and shrinkage during the drying of colloidal capillary-porous cylindrical bodies under conditions of equitable winding by a coolant are developed. The mathematical model was based on the differential equation of substance (energy, mass, impulse) transfer in deformable systems. It includes the equations diffusion-filtration transfer of energy for the system as a whole, and the mass transfer of the liquid, vapor and air phases in the pores of the body. Expressions for the intensity of evaporation of a liquid, capillary pressure, and the diffusion coefficients are presented. The relative volume strain was found by means of an analytical solution of the thermoconcentration deformation equation. Based on the explicit three-layer counting difference scheme and the procedure splitting of algorithm by physical factors, a numerical method for realizing this mathematical model is developed.

Experimental studies of the kinetics of dehydration of energy willow particles in the airflow were carried out to verify the mathematical model. Its applicability for calculating combined processes of drying and of the initial stage of thermal decomposition of biomass is substantiated. Using the previously obtained data on the activation energy values for various types of biomass, a mathematical simulation of the dynamics and kinetics of hightemperature drying in the flue gas flow of energy willow was carried out, which is accompanied by thermal destruction of hemiocellulose. The results of numerical experiments indicate the adequacy of the proposed approach, the effectiveness of the mathematical model and the method of its implementation. On their basis, it is possible to study the dynamics of heat and mass transfer when drying particles of different types of ground biomass; determination of the temperature of the beginning and ending of the first stage of thermal decomposition; the moment when the equilibrium moisture content is reached, depending on the properties of the material and the drying agent. These data allow choosing the process parameters that are optimal in terms of energy saving and quality of the dried product.
\end{abstract}

Keywords: biomass, drying, thermal destruction, mathematical modeling, cylindrical particle, drum dryer, activation energy.

Введение. Использование биомассы растительного и древесного происхождения в качестве сырья 


\section{Одеська національна академія харчових технологій МОДЕЛЮВАННЯ КОМБІНОВАНИХ ПРОЦЕСІВ ПЕРЕНОСУ. ОПТИМІЗАЦІЯ ОБЛАДНАННЯ І СИСТЕМ}

для получения топливных брикетов и гранул имеет большой потенциал в возобновляемой энергетике Украины. Для получения пеллет высокого качества сырье должно иметь влажность 8 - 12\%. В большинстве видов биомассы (солома, стебли кукурузы, подсолнечника, древесная стружка, энергетическая верба, сорго, мискантус) исходное содержание влаги по отношению к общей массе составляет 50 - 60\%. Сушка биомассы осуществляется преимущественно в барабанных сушильных

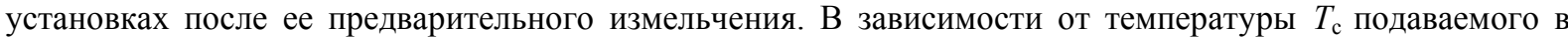

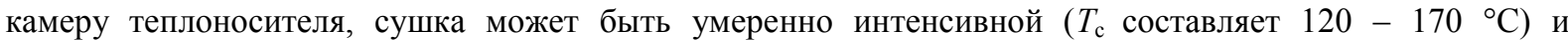
высокотемпературной (при $T_{\mathrm{c}} 300-500{ }^{\circ} \mathrm{C}$ ). В последнем случае обезвоживание биомассы сопровождается процессом ее термического разложения, начальная стадия которого характеризуется разложением гемицеллюлозы с выделением кислородосодержащих газов и пирогенетической влаги, что способствует повышению калорийности сухого остатка и соответственно биотоплива в целом. На последующих стадиях термодеструкции, при температурах выше $270{ }^{\circ} \mathrm{C}$ начинают разлагаться целлюлоза и лигнин, причем эти процессы в присутствии воздуха являются экзотермическими для всех видов биомассы и их интенсивное прохождение может привести к быстрому повышению температуры и существенной потере горючей составляющей. Поэтому важным моментом при разработке технологий высокотемпературной сушки биомассы является соблюдение условия прохождения первого этапа ее термического разложения и завершение процесса по достижении температуры, соответствующей последующим стадиям деструкции для данного вида биомассы.

Формулировка проблемы и анализ последних достижений. Создание сушильных технологий требует детального изучения явлений тепломассопереноса и фазовых превращений в высушиваемом материале при определенных условиях. Разработка технологий высокотемпературной сушки предполагает знание кинетических характеристик термического разложения данного вида биомассы в указанном интервале температур. Возможности экспериментальных методов исследования кинетики высокоинтенсивной сушки и термодеструкции в частицах малого размера весьма ограничены. Более перспективным методом исследования является математическое моделирование. Необходимость разработки математической модели совмещенных процессов сушки и термического разложения обоснована в [1].

В [2] была построена математическая модель и метод расчета динамики диффузионной сушки капиллярно-пористых тел в форме ограниченного цилиндра. Частицы всех видов биомассы представляют собой коллоидные капиллярно-пористые тела, а сушка в высокотемпературном сушильном агенте предполагает прохождение процессов переноса вследствие диффузии, фильтрации и фазовых превращений. Пирогенетическая вода удаляется вместе с остатками свободной и связанной влаги биомассы. В [3] были определены кинетические параметры десорбции физически связанной влаги и активационных процессов неизотермического разложения гемицеллюлозы древесной и растительной биомассы, которые свидетельствуют о том, что начало процесса термического разложения сопровождается резким повышением эффективной энергии активации частиц связанного вещества. Учет в математической модели этого явления позволит определять динамику тепломассопереноса при сушке частиц измельченной биомассы; температуру начала и окончания первой стадии термического разложения; момент достижения равновесного влагосодержания в зависимости от свойств материала и сушильного агента. На основе этих данных должны выбираться оптимальные с точки зрения сохранения энергии и качества режимные параметры процесса.

Основное исследование. Обычно барабанные сушильные аппараты оснащены лопаточными устройствами, которые способствуют интенсивному перемешиванию сырья и равномерному обдуву теплоносителем каждой частицы. Форма измельченных частиц биомассы имеет вид полых или сплошных цилиндров конечной длины. Математическая модель тепло- и массопереноса при обезвоживании коллоидных капиллярно-пористых частиц строится на базе уравнения переноса субстанции для деформируемых систем [4]

$$
\begin{aligned}
& c_{\text {эф }}\left(\frac{\partial T}{\partial t}+w_{\text {эф }} r \frac{\partial T}{\partial r}+w_{\text {эф } y} \frac{\partial T}{\partial y}\right)=\frac{1}{r} \frac{\partial}{\partial r}\left(\lambda_{\text {эф }} r \frac{\partial T}{\partial r}\right)+\frac{\partial}{\partial y}\left(\lambda_{\text {эф }} \frac{\partial T}{\partial y}\right)-L I_{V}, \\
& \frac{\partial U_{\text {ж }}}{\partial t}+\frac{\partial\left(w_{\text {ж } ~} U_{\text {ж }}\right)}{\partial r}+\frac{\partial\left(w_{\text {ж } y} U_{\text {ж }}\right)}{\partial y}=\frac{1}{r} \frac{\partial}{\partial r}\left(D_{ж} r \frac{\partial U_{\text {ж }}}{\partial r}\right)+\frac{\partial}{\partial y}\left(D_{\text {ж }} \frac{\partial U_{\text {ж }}}{\partial y}\right)-I_{V}-\frac{U_{\text {ж }}}{1-\varepsilon_{V}} \frac{\partial \varepsilon_{V}}{\partial t} \text {, } \\
& \frac{\partial U_{\Pi}}{\partial t}+\frac{\partial\left(w_{\Gamma} U_{\Pi}\right)}{\partial r}+\frac{\partial\left(w_{\Gamma y} U_{\Pi}\right)}{\partial y}=\frac{1}{r} \frac{\partial}{\partial r}\left(D_{\Pi} r \frac{\partial U_{\Pi}}{\partial r}\right)+\frac{\partial}{\partial y}\left(D_{\Pi} \frac{\partial U_{\Pi}}{\partial y}\right)+I_{V}-\frac{U_{\Pi}}{1-\varepsilon_{V}} \frac{\partial \varepsilon_{V}}{\partial t}, \\
& \frac{\partial U_{\mathrm{B}}}{\partial t}+\frac{\partial\left(w_{\Gamma} U_{\mathrm{B}}\right)}{\partial r}+\frac{\partial\left(w_{\Gamma} U_{\mathrm{B}}\right)}{\partial y}=\frac{1}{r} \frac{\partial}{\partial r}\left(D_{\mathrm{B}} r \frac{\partial U_{\mathrm{B}}}{\partial r}\right)+\frac{\partial}{\partial y}\left(D_{\mathrm{B}} \frac{\partial U_{\mathrm{B}}}{\partial y}\right)-\frac{U_{\mathrm{B}}}{1-\varepsilon_{V}} \frac{\partial \varepsilon_{V}}{\partial t} .
\end{aligned}
$$

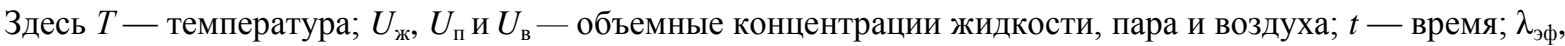
$c_{\text {эф }}$ - эффективные теплоемкость и теплопроводность и тела, $c_{\text {эф }}=c_{\mathrm{T}} U_{\mathrm{T}}+c_{\text {ж }} U_{\text {ж }}+c_{\text {п }} U_{\text {п }}+c_{\mathrm{B}} U_{\mathrm{B}}$, 


\section{Одеська начіональна академія харчових технологій МОДЕЛЮВАННЯ КОМБІНОВАНИХ ПРОЦЕСІВ ПЕРЕНОСУ. ОПТИМІЗАЦІЯ ОБЛАДНАННЯ І СИСТЕМ}

$\lambda_{\text {эф }}=\lambda_{\mathrm{T}} U_{\mathrm{T}} / \rho_{\mathrm{T}}+\lambda_{\text {ж }} U_{\text {ж }} / \rho_{\text {ж }}+\lambda_{\Pi} U_{\Pi} / \rho_{\Pi}+\lambda_{\mathrm{B}} U_{\mathrm{B}} / \rho_{\mathrm{B}} ; D_{\text {ж}}, D_{\Pi}, D_{\mathrm{B}}$ - эффективные коэффициенты диффузии компонентов, $D_{ж}=\gamma_{D}\left[\exp \left(A_{D} / R T\right)-1\right]^{-1}$ (формула Н.И.Никитенко [5]), $D_{\Pi}=D_{\text {в }}=\gamma_{\Pi} T^{3 / 2} / P_{\Gamma}$, $A_{D}$ - энергия активации; $I_{V}$ - интенсивность испарения жидкости в теле; $L-$ удельная теплота испа-

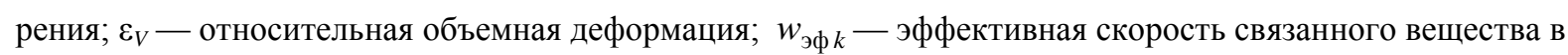
направлении $k(k=r, y), w_{\text {эф } k}=\left[w_{\text {ж } k} c_{\text {ж }} U_{\text {ж }}+w_{г k}\left(c_{\Pi} U_{\text {п }}+c_{\mathrm{B}} U_{\mathrm{B}}\right)\right] / c_{\text {эф }} \cdot$

Скорости фильтрации $w_{\psi}$ жидкой и газовой фаз ( $\left.\psi=ж, ~ г\right)$ находятся по закону Дарси: $w_{\psi}=-K_{0} K_{\psi} / \eta_{\psi} \nabla P_{\psi}$, где $K_{0}$ - общая проницаемость среды; $K_{\psi}$ - относительная проницаемость фазы $\psi ; \eta_{\psi}$ - динамический коэффициент вязкости фазы $\psi, P_{\psi}$ - парциальное давление фазы $\psi$. Для нахож-

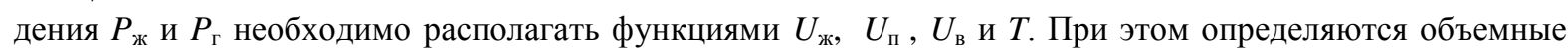

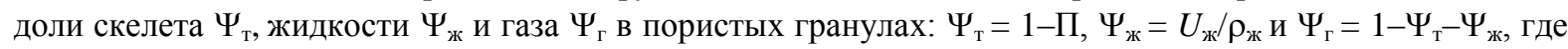
П - пористость, $\rho_{ж}$ - плотность жидкости. Далее рассчитываются парциальные плотности пара и воздуха $\rho_{\text {п }}=U_{\text {п. }} / \Psi_{г}, \rho_{\mathrm{B}}=U_{\mathrm{B}} / \Psi_{\mathrm{r}}$, а затем парциальные давления $P_{\mathrm{n}}=\rho_{\text {п }} R_{\mathrm{y}} T / \mu_{\text {п }}$ и $P_{\mathrm{B}}=\rho_{\mathrm{B}} R_{\mathrm{y}} T / \mu_{\mathrm{B}}$. Давление газовой смеси представляется суммой $P_{\mathrm{r}}=P_{\text {п }}+P_{\mathrm{B}}$, а давление жидкой фазы равно $P_{\text {ж}}=P_{\mathrm{r}}+P_{\mathrm{\kappa}}$. Капиллярное давление $P_{\kappa}$ находится как среднее капиллярное давление жидкости [4]: $P_{\mathrm{\kappa}}=\int_{r_{\min }}^{r_{\max }} P_{\text {кл }} d V / \int_{r_{\min }}^{r_{\max }} d V$. Объем жидкости в капиллярах с радиусами от $r$ до $r+d r$ в единичном объеме тела пропорционален дифференциальной функции $F(r)$ распределения пор по размерам $d V(r)=\theta(r) F(r) d r$, где $\theta(r)$ - объемная доля капилляра, занятая жидкостью. В результате получаем выражение, аналогичное формуле Лапласа

$$
P_{\mathrm{\kappa}}=2 \sigma(T) \int_{r_{\min }}^{r_{\max }} \frac{\theta(r)}{r} F(r) d r / \int_{r_{\min }}^{r_{\max }} \theta(r) F(r) d r=\frac{2 \sigma(T)}{r^{*}}, \quad r_{\min }<r^{*}<r_{\max } .
$$

Здесь $r_{\min }$ и $r_{\max }$ - минимальный и максимальный радиусы пор единичного объема, $r^{*}-$ характерестический параметр дисперсности размеров пор.

Интенсивность испарения жидкости на внешних поверхностях частиц биомассы [6] находится как разность потоков испаряющейся жидкости и конденсирующегося пара

$$
I=\gamma_{\mathrm{c}}\left\{\left.\varphi_{\mathrm{T}}\right|_{\nu=0}\left(\exp \left[A /\left(\left.R T\right|_{\nu=0}\right)\right]-1\right)^{-1}-\varphi_{\mathrm{c}}\left(\exp \left[A /\left(R T_{\mathrm{c}}\right)\right]-1\right)^{-1}\right\}, \gamma_{\mathrm{c}}=\varepsilon \rho_{\text {ж}} \delta^{*} / 4
$$

Здесь $\gamma_{\mathrm{c}}$ - коэффициент поверхностного испарения; $\varepsilon-$ коэффициент излучения, $1 / \mathrm{c} ; \delta$ * средняя длина диффузионного перескока активизированной частицы в слое жидкости; $\varphi_{\mathrm{T}}$ - влажность парогазовой смеси, которая соответствует согласно изотерме сорбции концентрации $U_{\text {ж }}$ данной точке тела; $v$ - нормаль к поверхности; $T_{\mathrm{c}}$ и $\varphi_{\mathrm{c}}$ - температура и относительная влажность внешней среды; $A-$ энергия активации.

Выражение для интенсивности испарения в единичном объеме тела следует из формулы (6) при условии локального термодинамического равновесия

$$
I_{V}=\gamma_{\mathrm{c}}[\exp (A / R T)-1]^{-1}\left(\varphi_{\mathrm{T}}-\varphi\right) S .
$$

Здесь $S$ - площадь контакта жидкой и газовой фаз в порах тела не полностью заполненных жидкостью.

Для нахождения функции $S$ в единичном объеме тела в работе [7] получена формула

$$
S=\frac{2 \sqrt{1-\varphi_{\mathrm{T}}}}{\rho_{\text {ж }} \delta} \frac{\partial U_{ж}}{\partial \varphi_{\mathrm{T}}}
$$

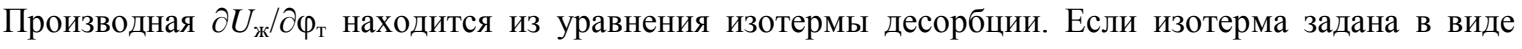
$U_{\text {ж }}=U_{\max } \varphi_{\mathrm{T}}^{\mathrm{g}}, \mathrm{g}=\mathrm{const}$, то $\partial U_{\text {ж}} / \partial \varphi_{\mathrm{T}}=U_{\max } \mathrm{g} \varphi_{\mathrm{T}}^{\mathrm{g}-1}$. Данные по равновесному влагосодержанию для древесины представленные в [8] довольно точно описывается уравнением $W^{-1}=W_{\max }^{-1}-0,12 \ln \varphi$, где максимальное влагосодержание $W_{\max }$ соответствует $\varphi=1$ и при температуре $100{ }^{\circ} \mathrm{C}$ составляет $16 \%$, а $U_{\text {ж }}=$ $0,01 W \rho_{\mathrm{T}}$.

Относительная объемная деформация $\varepsilon_{V}$ находится с помощью аналитического решения осесимметричной задачи о напряженном состоянии полого цилиндра, полученного в [9] при условии, что деформации происходят вследствие неоднородности полей температуры и концентрации компонентов связанного вещества, а также под влиянием равномерно распределенных давлений: $P_{0}$ на внутренней цилиндрической поверхности радиуса $r=r_{0}, P$ на внешней поверхности радиуса $r=R$ и результирующей силы $P_{z}$ вдоль оси цилиндра $z$ : 


$$
\begin{gathered}
u_{r}(r)=\frac{1}{r\left(1-v_{\Pi}\right)}\left[\left(1+v_{\Pi}\right) \int_{r_{0}}^{r} N r d r+\frac{r^{2}\left(1-3 v_{\Pi}\right)+r_{0}^{2}\left(1+v_{\Pi}\right)}{R^{2}-r_{0}^{2}} \int_{r_{0}}^{R} N r d r+\frac{r v_{\Pi} P_{z}}{E_{\mathrm{y}} \pi\left(R^{2}-r_{0}^{2}\right)}\right]+ \\
+\frac{1}{E_{\mathrm{y}} r\left(R^{2}-r_{0}^{2}\right)}\left[r^{2}\left(1-v_{\Pi}\right)\left(P_{0} r_{0}^{2}-P R^{2}\right)+\left(1+v_{\Pi}\right) r_{0}^{2} R^{2}\left(P_{0}-P\right)\right], \\
\varepsilon_{z}=\frac{2}{R^{2}-r_{0}^{2}} \int_{r_{0}}^{R} N r d r-\frac{2 v_{\Pi}}{E_{\mathrm{y}}} \frac{P_{0} r_{0}^{2}-P R^{2}}{R^{2}-r_{0}^{2}}-\frac{P_{z}}{E_{\mathrm{y}} \pi\left(R^{2}-r_{0}^{2}\right)},
\end{gathered}
$$

где $u_{r}, \varepsilon_{z}$ - проекции вектора перемещения на оси $r$ и $z ; v_{\Pi}-$ коэффициент Пуассона; $E_{y}-$ модуль упругости; $N$ - термоконцентрационная функция [7, 9], $N=\beta_{T}\left(T-T_{0}\right)+\sum_{\psi} \beta_{\psi}\left(\omega_{\psi}-\omega_{\psi 0}\right), \omega_{\psi}-$ массосодержание компонента $\psi, \beta_{T}=(\partial x / \partial T) / x$ и $\beta_{\psi}=\left(\partial x / \partial \omega_{\psi}\right) / x-$ средние коэффициенты термического и концентрационного расширения в интервалах температуры $\left[T, T_{0}\right]$ и массовой концентрации компонента $\psi\left[\omega_{\psi}, \omega_{\psi 0}\right]$. При $r_{0}=0,(9)$ и (10) представляют решение задачи термоконцентрационной упругости для сплошного цилиндра. Нормальные компоненти тензора деформаций $\varepsilon_{r r}, \varepsilon_{\varphi \varphi}$ и $\varepsilon_{z z}$ находятся из соотношений $\varepsilon_{r r}=\partial u_{r} / \partial r, \quad \varepsilon_{\varphi \varphi}=u_{r} / r, \quad \varepsilon_{z z}=\partial u_{z} / \partial z=\varepsilon_{z}$, откуда $\left.\varepsilon_{V}(t)=\left[1+\varepsilon_{r r}(t)\right]\left[1+\varepsilon_{\varphi \varphi}(t)\right]\left[1+\varepsilon_{z z}(t)\right]-1\right]$. Если тело является капиллярно-пористым, его усадкой в процессе сушки можно пренебречь и $\varepsilon_{V}=0$.

Условия тепломассообмена на границе $r=0$ для сплошного цилиндра представляют условия симметрии полей температуры, концентраций и скоростей фильтрации компонентов связанного вещества

$$
\left.\frac{\partial T}{\partial r}\right|_{v=0}=0,\left.\frac{\partial U_{\text {ж}}}{\partial r}\right|_{v=0}=0,\left.\frac{\partial U_{\Pi}}{\partial r}\right|_{v=0}=0,\left.\frac{\partial U_{\mathrm{B}}}{\partial r}\right|_{v=0}=0,\left.\frac{\partial w_{\text {жr }}}{\partial r}\right|_{v=0}=0 ;\left.\frac{\partial w_{\mathrm{rr}}}{\partial r}\right|_{v=0}=0 .
$$

На поверхностях, контактирующих с сушильным агентом задаются граничные условия третьего рода

$$
\begin{aligned}
& \left.\lambda_{\text {эф }} \frac{\partial T}{\partial v}\right|_{\nu=0}=\alpha\left(T_{\mathrm{c}}-\left.T\right|_{\nu=0}\right)-L \gamma_{\mathrm{c}}\left\{\left.\varphi_{\mathrm{T}}\right|_{v=0}\left[\exp \left(\frac{A}{\left.R T\right|_{\nu=0}}\right)-1\right]^{-1}-\varphi_{\mathrm{c}}\left[\exp \left(\frac{A}{R T_{\mathrm{c}}}\right)-1\right]^{-1}\right\}, \\
& \left.D_{\text {ж }} \frac{\partial U_{\text {ж }}}{\partial v}\right|_{v=0}=\gamma_{\mathrm{c}}\left\{\left[\left.\varphi_{\mathrm{T}}\right|_{v=0} \exp \left(\frac{A}{\left.R T\right|_{\mathrm{v}=0}}\right)-1\right]^{-1}-\varphi_{\mathrm{c}}\left[\exp \left(\frac{A}{R T_{\mathrm{c}}}\right)-1\right]^{-1}\right\}, \\
& -\left.D_{\Pi} \frac{\partial U_{\Pi}}{\partial v}\right|_{v=0}=\gamma_{\Pi \mathrm{C}}\left(\left.U_{\Pi}\right|_{v=0}-\rho_{\text {пс }} \psi_{\Pi}\right),\left.\quad U_{\mathrm{B}}\right|_{v=0}=\frac{P_{\mathrm{c}} \psi_{\mathrm{r}} \mu_{\mathrm{B}}}{\left.R T\right|_{v=0}}-\left.U_{\Pi}\right|_{v=0} \frac{\mu_{\mathrm{B}}}{\mu_{\Pi}}
\end{aligned}
$$

Коэффициент теплоотдачи $\alpha$ определялся $\mathrm{c}$ использованием формулы $[10] \quad \mathrm{Nu}=$ $0,98\left(0,43+0,55 \mathrm{Re}^{0,5} \mathrm{Pr}^{0,38}\right)$. Для поверхности $r=r_{0}$ при $T_{\mathrm{c}}=$ const можно принять $\mathrm{Nu}=3,66[10]$.

Решение дифференциальных уравнений (1) - (4) при граничных условиях (11) - (14) может быть проведено численным методом на базе явной трехслойной пересчетной разностной схемы Никитенко Н.И. [7] и процедуре расщепления алгоритма по физическим факторам. Разностная аппроксимация уравнения переноса жидкой фазы (2) на равномерной разностной сетке $r_{i}=R_{\mathrm{BH}}+i h,\left(i=0,1, \ldots, I ; h=\right.$ const, $R_{\mathrm{BH}}$ $>0), x_{m}=m h_{y},\left(m=0,1, \ldots, M ; h_{y}=\right.$ const $), t_{n}=n l(n=0,1, \ldots, l>0)$ в соответствии с указанной схемой представляется в виде

$$
\begin{aligned}
& \frac{\bar{U}_{\text {ж,i,m }}^{n+1}-U_{\text {Ж,i,m }}^{n}}{l}=-\left[\left(\left(w_{\text {жr }} U_{\text {Ж }}\right)_{i+1, m}^{n}-\left(w_{\text {жr }} U_{\text {Ж }}\right)_{i, m}^{n}\right)-\left(\left(w_{\text {жr }} U_{\text {Ж }}\right)_{i, m}^{n}-\left(w_{\text {жr }} U_{\text {Ж }}\right)_{i-1, m}^{n}\right)\right] /\left(2 h^{2}\right)- \\
& -\left[\left(\left(w_{\text {жу }} U_{\text {ж }}\right)_{i, m+1}^{n}-\left(w_{\text {жу }} U_{\text {ж }}\right)_{i, m}^{n}\right)-\left(\left(w_{\text {жу }} U_{\text {ж }}\right)_{i, m}^{n}-\left(w_{\text {жу }} U_{\text {ж }}\right)_{i, m-1}^{n}\right)\right] /\left(2 h_{y}^{2}\right),
\end{aligned}
$$

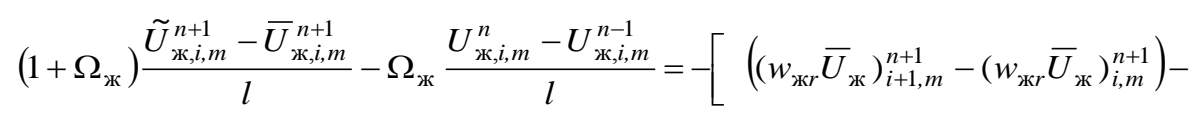




$$
\begin{aligned}
& \left.\left(\left(w_{\text {жr }} \bar{U}_{\text {ж }}\right)_{i, m}^{n+1}-\left(w_{\text {жr }} \bar{U}_{\text {ж }}\right)_{i-1, m}^{n+1}\right)\right] /\left(2 h^{2}\right)-\left[\left(\left(w_{\text {жу }} \bar{U}_{\text {ж }}\right)_{i, m+1}^{n+1}-\left(w_{\text {жу }} \bar{U}_{\text {ж }}\right)_{i, m}^{n+1}\right)-\right. \\
& \left.-\left(\left(w_{\text {жу }} \bar{U}_{\text {ж }}\right)_{i, m}^{n+1}-\left(w_{\text {жу }} \bar{U}_{\text {ж }}\right)_{i, m-1}^{n+1}\right)\right] /\left(2 h_{y}^{2}\right)+\frac{1}{2 r_{i, m}}\left[\left(D_{\text {ж,i+1,m }} r_{i+1, m}+D_{\text {ж,i,m }} r_{i, m}\right)\left(\bar{U}_{\text {ж,i+1,m }}^{n+1}-\bar{U}_{\text {ж,i,m }}^{n+1}\right)-\right. \\
& \left.-\left(D_{ж, i, m} r_{i, m}+D_{\%, i-1, m} r_{i-1, m}\right)\left(\bar{U}_{\%, i, m}^{n+1}-\bar{U}_{\%, i-1, m}^{n+1}\right)\right] / h^{2}+\left\lfloor\left(D_{ж, i, m+1}+D_{ж, i, m}\right)\left(\bar{U}_{\%, i, m+1}^{n+1}-\bar{U}_{\%, i, m}^{n+1}\right)-\right. \\
& \left.\left(D_{ж, i, m}+D_{ж, i, m-1}\right)\left(\bar{U}_{ж, i, m}^{n+1}-\bar{U}_{\%, i, m-1}^{n+1}\right)\right] /\left(2 h_{y}^{2}\right)-I_{V} \\
& \frac{U_{\aleph_{i}}^{n+1}-\tilde{U}_{\aleph_{i}}^{n+1}}{l}=\frac{\tilde{U}_{\varkappa_{i}}^{n+1}}{1+\varepsilon_{V}} \frac{\varepsilon_{V}^{n+1}-\varepsilon_{V}^{n}}{l} .
\end{aligned}
$$

Аналогичным образом аппроксимируются дифференциальные уравнения (3), (4), а уравнение переноса энергии (1), не содержащее функцию $\varepsilon_{V}$ аппроксимируется первыми двумя разностными уравнениями.

Необходимые условия устойчивости уравнений вида (15) - (17) находятся методом условного задания некоторых искомых функций системы [7]: $l_{\text {ж }} \leq\left\{\left(w_{\text {ж } r} / h+w_{\text {ж } y} / h_{y}\right)^{-1} ;\left(1+2 \Omega_{\text {ж }}\right) /\left[2 D_{\text {ж }}\left(h^{-2}+h_{y}^{-2}\right)\right]\right\}$. Расчетный шаг по времени определяется из условия $l \leq \min \left(l_{T} ; l_{\text {ж}} ; l_{\text {п }} ; l_{\mathrm{B}}\right)$.

Разностная аппроксимация граничного условия (13) для поверхности $r=R$ представляется в виде

$$
D_{\text {ж }} \frac{\bar{U}_{Ж I}^{n+1}-\bar{U}_{Ж I-1}^{n+1}}{h}=\gamma_{\mathrm{c}}\left\{\varphi_{\mathrm{TI}}\left[\exp \left(A / R_{\mathrm{y}} \bar{T}_{I}^{n}\right)-1\right]^{-1}-\varphi_{\mathrm{c}}\left[\exp \left(A / R_{\mathrm{y}} T_{\mathrm{c}}\right)-1\right]^{-1}\right\} .
$$

Обсуждение результатов. Для подтверждения адекватности разработанной математической модели и эффективности численного метода расчета было проведено физическое моделирование кинетики сушки частиц энергетической вербы цилиндрической формы в потоке воздуха и математическое моделирование процесса при тех же исходных данных: $T_{0}=303 \mathrm{~K} ; W_{0}=1,3$ кг/кг; $\lambda_{\mathrm{T}}=0,15$ Вт/(м·К); $c_{\mathrm{T}}=1840$ Дж/(кг $\cdot$ К); $\rho_{\mathrm{T}}=450 \mathrm{\kappa} / \mathrm{M}^{3} ; A=A_{D}=0,4205 \cdot 10^{8}$ Дж/кмоль; $\Pi=0,58$. Результаты расчета и экспериментальные данные, представленные на рис. 1 , достаточно хорошо согласуются.

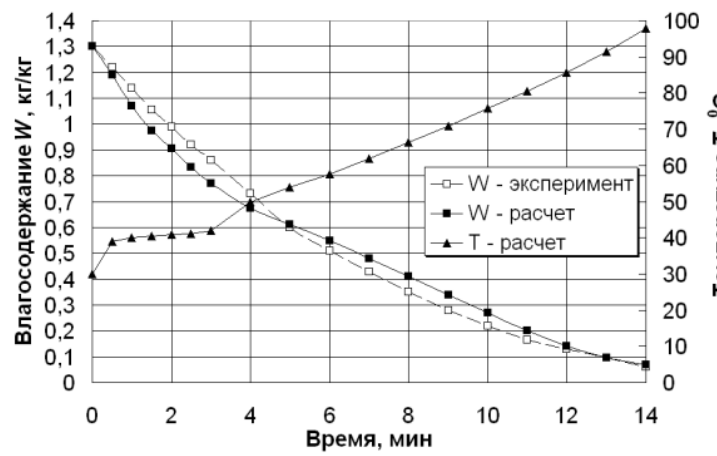

a) $d / h=4,2 / 10 \mathrm{MM}$

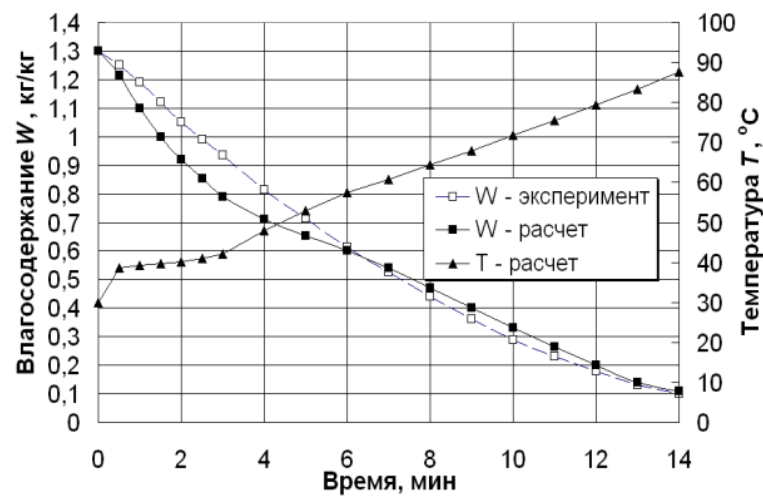

б) $d / h=5,6 / 10 \mathrm{MM}$

Рис. 1. Изменение во времени средних значений влагосодержания $W$ и температуры $T$ частиц энергетической вербы цилиндрической формы различного диаметра при сушке в потоке воздуха с параметрами $T_{\mathrm{c}}=120^{\circ} \mathrm{C}, w_{\mathrm{c}}=2 \mathrm{M} / \mathrm{c}, d_{\mathrm{c}}=18$ г/кг с.в.

Далее проводился расчет высокотемпературной сушки без учета термического разложения, а также сушки и начального этапа термического разложения энергетической вербы в потоке дымовых газов в условиях равномерного обдува частиц.

Температура теплоносителя задавалась в интервале $300-500{ }^{\circ} \mathrm{C}$. При расчете совместных процессов сушки и термодеструкции в математической модели по достижении материалом температуры $150{ }^{\circ} \mathrm{C}$ (начала проявления термодеструкции) менялось значение энергии активации физико-химически связанной с телом воды на среднее эффективное значение, соответствующее температурному интервалу разложения гемиоцеллюлоз, определенное из эксперимента [3]. 


\section{Одеська начіональна академія харчових технологій \\ МОДЕЛЮВАННЯ КОМБІНОВАНИХ ПРОЦЕСІВ ПЕРЕНОСУ. ОПТИМІЗАЦІЯ ОБЛАДНАННЯ І СИСТЕМ}

Для лиственных пород деревьев $A_{\text {эф }}=A_{D э ф}=0,7525 \cdot 10^{8}$ Дж/кмоль. На рис. 2 представлены результаты численных экспериментов.

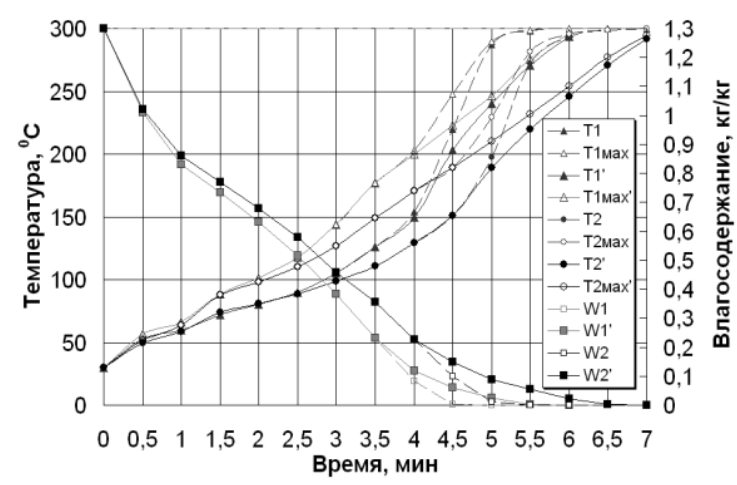

a) $T_{c}=300^{\circ} \mathrm{C}$

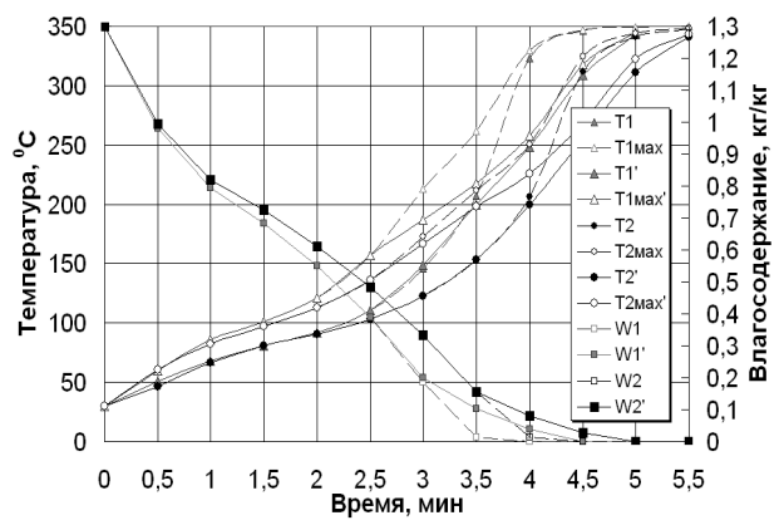

б) $T_{c}=350^{\circ} \mathrm{C}$

Рис. 2. Изменение во времени средних значений влагосодержания $W$, температуры $T$, и макси-

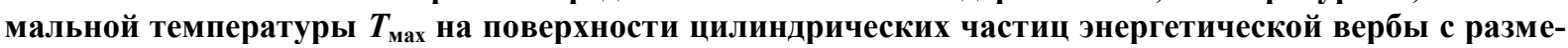
рами $d / h=4,2 / 10$ мм (кривые 1$)$ и $d / h=5,6 / 10$ мм (кривые 2) при сушке без учета термодеструкции и с ее учетом $\left(W^{\prime}, T^{\prime}, T_{\max }{ }^{\prime}\right)$ в потоке дымовых газов с параметрами $w_{\mathrm{c}}=2 \mathrm{м} / \mathrm{c}, d_{\mathrm{c}}=18$ г/кг с.в.

Выводы. Процесс термического разложения, как и процессы диффузии и испарения, является активационным. Вследствие того, что энергия активации, необходимая для перехода частиц гемиоцеллюлозы в свободное состояние существенно выше, чем энергия активации частиц связанной воды, расчет высокотемпературной сушки биомассы необходимо проводить с учетом проявляющегося на заключительной стадии обезвоживания первого этапа термического разложения. Разработанная математическая модель и метод расчета процессов тепломассопереноса, фазовых превращений и деформирования при обезвоживании цилиндрических коллоидных капиллярно-пористых тел позволяет учесть влияние термического разложения на динамику изменения влагосодержания и температуры материала биомассы, оптимизировать технологический процесс сушки биомассы и повысить калорийность получаемого из нее биотоплива.

\section{Литература}

1. Снєжкін Ю.Ф., Корінчук Д.М., Безгін М.М. Дослідження режимів термообробки біомаси та торфу у виробництві композиційного біопалива // Пром. теплотехніка. 2017. Т. 39, №1. С 53 - 57.

2. Сорокова Н.М. Математичне моделювання динаміки сушіння капілярно-пористих тіл циліндричної форми кінцевої довжини // Харчова промисловість. 2008. №6. С. $67-69$.

3. Коринчук Д.Н. Неизотермический анализ компонентов композиционных топлив на основе торфа и биомассы // Енергетика i автоматика. 2018. №1. С. 56-71.

4. Никитенко Н.И., Снежкин Ю.Ф., Сороковая Н.Н. Математическое моделирование тепломассопереноса, фазовых превращений и усадки с целью оптимизации процесса сушки термолабильных материалов // ИФЖ. 2005. Т. 78, № 1. С. 74 - 87.

5. Никитенко Н.И. Проблемы радиационной теории тепло- и массопереноса в твердых и жидких средах // ИФЖ. 2000. Т. 736 № 4. C. $851-839$.

6. Никитенко Н.И. Исследование динамики испарения конденсированных тел на основе закона интенсивности спектрального излучения частиц// ИФЖ. 2002. Т.75б № 3. С. 128-134.

7. Никитенко Н.И., Снежкин Ю.Ф., Сороковая Н.Н., Кольчик Ю.Н. Молекулярно-радиационная теория и методы расчета тепло- и массообмена. Киев: Наукова думка, 2014. 744 с.

8. Лыков А.В. Теория сушки. М.: Энергия, 1968. 372 с.

9. Никитенко Н.И., Кольчик Ю.Н. Метод канонических элементов для моделирования переносных процессов в многосвязных областях произвольной формы. Инж.-физ. журн. 1999. Т.72, № 5. С. $837-843$.

10. Исаченко В.П., Осипова В.А., Сукомел А.С. Теплопередача. М.: Энергоиздат, 1981. 416 с.

\section{References}

1. Sniezhkin Yu.F., Korinchuk D.M., Bezghin M.M. (2017) Doslidzhennia rezhymiv termoobrobky biomasy ta torfu u vy-robnytstvi kompozytsinoho biopalyva. Prom. teplotekhnika. 39(1), $53-57$.

2. Sorokova N.M. (2008) Matematychne modeliuvannia dynamiky sushinnia kapiliarno-porystykh til tsylindrychnoi formy kintsevoi dovzhyny. Kharchova promyslovist.. 6, 67 - 69 .

3. Korinchuk D.N. (2018) Neizotermicheskiy analiz komponentov kompozitsionnyih topliv na osnove torfa i biomassyi. Enerhetyka i avtomatyka. $1,56-71$.

4. Nikitenko N.I., Snezhkin Yu.F., Sorokovaya N.N. (2005) Matematicheskoe modelirovanie teplomassoperenosa, fazovyih prevrascheniy i usadki s tselyu optimizatsii protsessa sushki termolabilnyih materialov. Inzh.fiz. zhurn., 78(1), $74-87$.

5. Nikitenko N.I. (2000) Problemyi radiatsionnoy teorii teplo- i massoperenosa v tverdyih i zhidkih sredah. Inzh.-fiz. zhurn., 73(4), 851839.

6. Nikitenko N.I. (2002) Issledovanie dinamiki ispareniya kondensirovannyih tel na osnove zakona intensivnosti spektralnogo izlucheniya chastits. Inzh.fiz. zhurn., 75(3), 128-134. 


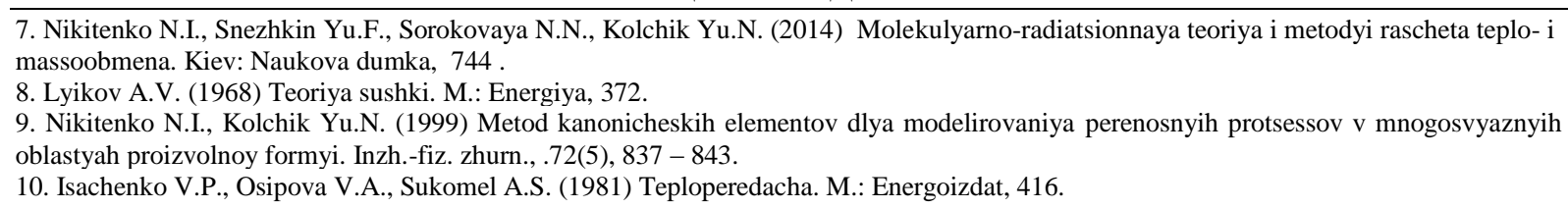

\title{
ДОСЛІДЖЕННЯ ГІДРОДИНАМІЧНИХ ХАРАКТЕРИСТИК ЕЛЕМЕНТІВ ЗАХИСТУ ХАРЧОВИХ ВИРОБНИЦТВ
}

\author{
Рябова І.Б. ${ }^{1}$, к.т.н., доцент, Петухова О.А. ${ }^{2}$, к.т.н., доцент, \\ Горносталь С.А. ${ }^{2}$, к.т.н., Щербак С.М. ${ }^{2}$ \\ ${ }^{1}$ Національний технічний університет «ХПІ», м. Харків \\ ${ }^{2}$ Національний університет цивільного захисту України, м. Харків
}

\begin{abstract}
Анотація. Важливою складовою собівартості продукиї харчових виробництв є елементи забезпечення їх безпечного виробництва, одним з яких являється внутрішній протипожежний водопровід, який обов'язковий для встановлення в приміщеннях харчових виробниитв з відповідною категорією за вибухопожежною та пожежною небезпекою, ступенем вогнестійкості та об'ємом виробничого корпусу. 3 введенням в дію ДБН В 2.5-64:2012 «Внутрішній водопровід та каналізація» кожна шафа окрім встановленого в ній пожежного кран-комплекту діаметром 50 або 65 мм, обов'язково комплектується додатковим пожежним кран-комплектом діаметром 25 або 33 мм, який призначений для швидкого введення вогнегасної речовини в початковій стадії розвитку пожежі, а тому забезпечує зниження збитків від неї. Додаткові кран-комплекти комплектуються рукавом (довжина рукава - до 30 м, діаметр рукава - 25 мм або 33 мм, тип рукава - напівжорсткий) та розпорошувачем (діаметр випускного отвору розпорошувача від 4 до 12 мм). До переваг таких пристроїв відносять невеликі габарити, застосування спеціальних насадок розпорошувача дозволяє створювати дрібнодисперсний струмінь води, який не пошкоджує оточуючи речи та обладнання, гнучкий рукав комплекту дозволяє обійти технологічні установки, щуо зустрічаються на шляху, установка перекривного пристрою дозволяє перервати роботу в будь-який момент і відновити ї̈ за необхідності, вартість вогнегасної речовини - води, як $і$ самої установки - невелика. В залежності від умов використання додаткового пожежного кран-комплекту різні характеристики його складових можуть забезпечити підвищення або зниження ефективності його роботи. Тому запропоновано спосіб визначення характеристик складових додаткового пожежного кран-комплекту для конкретних умов його експлуатаиії. Вірний вибір параметрів складових дозволить з урахуванням гідродинамічних характеристик системи, щу забезпечує роботу таких пристроїв, з найменшими економічними втратами забезпечити успішне гасіння пожежі та знизити збитки від неї.
\end{abstract}

Ключові слова: пожежний кран-комплект, тиск, витрати води, рукав, розпорошувач.

\section{STUDYING THE HYDRODYNAMIC CHARACTERISTICS OF PROTECTION ELEMENTS IN FOOD PRODUCTION}

\author{
Rjabova I.B. ${ }^{1}$, PhD, associate professor, Petukhova O.A. ${ }^{2}$, PhD, associate professor, \\ Gornostal S.A. ${ }^{2}$, PhD, Shcherbak S.M. ${ }^{2}$ \\ ${ }^{1}$ National Technical University «KPI», Kharkiv \\ ${ }^{2}$ National University of Civil Protection of Ukraine, Kharkiv
}

\begin{abstract}
An important component of the cost of food products is the elements of ensuring their safe production, one of which is the internal fire water supply, which is obligatory for installation in the premises of food production enterprises with the appropriate category for fire and fire hazard, fire resistance and the volume of the production building. With the introduction of the DBN V 2.5-64:2012 "Internal plumbing and sewage system", each cabinet, except for installed fire faucet with a diameter of 50 or $65 \mathrm{~mm}$, necessarily completes an additional fire faucet with a diameter of 25 or $33 \mathrm{~mm}$, which is designed for the rapid introduction of extinguishing agent in the initial stage of the development of the fire, and therefore provides a reduction of losses from it. Additional fire faucets are completed with a sleeve (length of the sleeve - up to $30 \mathrm{~m}$, diameter of the sleeve - 25 mm or $33 \mathrm{~mm}$, type of sleeve - semi-rigid) and the sprayer (diameter of the outlet of the sprayer from 4 to 12 $\mathrm{mm})$. The advantages of such devices include small dimensions. The use of special spray nozzles allows you to
\end{abstract}

Наукові праці, Том 82, випуск 1 Scientific Works, Volume 82, Issue 1 